\title{
Inhibitory Effect of a French Maritime Pine Bark Extract-Based Nutritional Supplement on TNF- $\alpha$-Induced Inflammation and Oxidative Stress in Human Coronary Artery Endothelial Cells
}

\author{
Kristine C. Y. McGrath, ${ }^{1}$ Xiao-Hong Li, ${ }^{1,2}$ Lucinda S. McRobb, ${ }^{3}$ and Alison K. Heather ${ }^{4}$ \\ ${ }^{1}$ Molecular Biosciences Team, School of Life Sciences, University of Technology Sydney, Broadway, NSW, Australia \\ ${ }^{2}$ Department of Endocrinology, Dezhou People's Hospital, Shandong, China \\ ${ }^{3}$ Department of Clinical Medicine, Macquarie University, Sydney, NSW 2109, Australia \\ ${ }^{4}$ Department of Physiology, Otago School of Medical Sciences, University of Otago, Dunedin, New Zealand
}

Correspondence should be addressed to Kristine C-Y. McGrath; kristine.mcgrath@uts.edu.au

Received 9 July 2015; Revised 19 October 2015; Accepted 20 October 2015

Academic Editor: José L. Ríos

Copyright (C) 2015 Kristine C-Y. McGrath et al. This is an open access article distributed under the Creative Commons Attribution License, which permits unrestricted use, distribution, and reproduction in any medium, provided the original work is properly cited.

\begin{abstract}
Oxidative stress and inflammation, leading to endothelial dysfunction, contribute to the pathogenesis of atherosclerosis. The popularity of natural product supplements has increased in recent years, especially those with purported anti-inflammatory and/or antioxidant effects. The efficacy and mechanism of many of these products are not yet well understood. In this study, we tested the antioxidant and anti-inflammatory effects of a supplement, HIPER Health Supplement (HIPER), on cytokine-induced inflammation and oxidative stress in human coronary artery endothelial cells (HCAECs). HIPER is a mixture of French maritime pine bark extract (PBE), honey, aloe vera, and papaya extract. Treatment for 24 hours with HIPER reduced TNF- $\alpha$-induced reactive oxygen species (ROS) generation that was associated with decreased NADPH oxidase 4 and increased superoxide dismutase1 expression. HIPER inhibited TNF- $\alpha$ induced monocyte adhesion to HCAECs that was in keeping with decreased expression of vascular cell adhesion molecule-1 and intercellular cell adhesion molecule- 1 and decreased nuclear factor-kappa B (NF- $\kappa$ B) activation. Further investigation of mechanism showed HIPER reduced TNF- $\alpha$ induced $\mathrm{I} \kappa \mathrm{B} \alpha$ and p38 and MEK1/2 MAP kinases phosphorylation. Our findings show that HIPER has potent inhibitory effects on HCAECs inflammatory and oxidative stress responses that may protect against endothelial dysfunction that underlies early atherosclerotic lesion formation.
\end{abstract}

\section{Introduction}

Chronic subacute inflammation and oxidative stress leading to endothelial dysfunction underlie the early pathogenesis of atherosclerosis $[1,2]$. A key early step in atherosclerotic lesion formation is the adhesion of monocytes to the endothelium and the subsequent migration of the monocytes into the subintima where they engulf oxidized LDL and become classical "foam cells" [3]. The interaction of monocytes with endothelial cells is mediated by cell adhesion molecules, the most important of which are vascular cell adhesion molecule-1 (VCAM-1) and intercellular cell adhesion molecule-1 (ICAM-1) expressed by the endothelial cells [4]. The expression of both VCAM-1 and ICAM-1 is regulated by nuclear factor-kappa B (NF- $\kappa \mathrm{B})$, a transcription factor that is activated by oxidative stress.

Inflammation and oxidative stress are considered key targets to improving or reversing endothelial dysfunction associated with early atherosclerotic plaque formation [1, 2]. In addition to main stream medical treatments, there is increasing popularity in using natural compounds for their intrinsic anti-inflammatory and antioxidant properties. HIPER Health Supplement (HIPER) was formulated using a combination of French maritime pine bark extract (Pinus pinaster, PBE), aloe vera, honey, and papain. For PBE, aloe vera, and honey, there is existing scientific literature supporting either anti-inflammatory or antioxidant properties [5-9]. In this study, we have investigated whether HIPER, 
a combination of these ingredients, could protect human coronary artery endothelial cells (HCAECs) from cytokineinduced inflammatory and oxidative stress responses. Our findings show that HIPER was effective in suppressing VCAM-1 and ICAM-1 expression, primarily via its effect on decreasing NF- $\kappa \mathrm{B}$ and MAP kinase activation. This antiinflammatory effect is most likely due to the effect of HIPER on lowering intracellular ROS levels.

\section{Materials and Methods}

2.1. HIPER Health Supplement. HIPER Health Supplement, as well as the individual components of aloe vera, honey, papain, and PBE, was kindly donated by Plasmaide Pty Ltd. (Sydney, NSW, Australia). The supplement was filtered through a $0.22 \mu \mathrm{m}$ pore size sterile syringe filter unit before use (Merck Millipore, Bayswater, VIC, Australia). HIPER was used at a volume of $25 \mu \mathrm{L}$ or $50 \mu \mathrm{L}$ per $\mathrm{mL}$ of media that equated to a $50 \mathrm{~mL}$ or $100 \mathrm{~mL}$ dose recommended for human consumption.

2.2. Cell Culture. HCAECs (Cell Applications, San Diego, CA, USA) were cultured in MesoEndo Cell Growth Medium (Cell Applications). HCAECs were pretreated with HIPER for $3 \mathrm{~h}$ at a dose of $6.25,12.5,25$, or $50 \mu \mathrm{L}$ per $\mathrm{mL}$ of media or phosphate-buffered saline (PBS; Astral Scientific, Sydney, NSW, Australia) as vehicle-control and then stimulated with TNF- $\alpha$ (1-5 ng/mL) (Sigma-Aldrich, Castle Hill, NSW, Australia) for $1 \mathrm{~h}$.

2.3. $R T-q P C R$. Total RNA was extracted using TRI reagent (Sigma-Aldrich) and the concentration was normalized to $100 \mathrm{ng} / \mu \mathrm{L}$ using a NanoDrop 1000 spectrophotometer (Thermo Fisher Scientific, Mulgrave, VIC, Australia). cDNA was generated from $100 \mathrm{ng}$ of total RNA using iSCRIPT (Bio-Rad, Regents Park, NSW, Australia). An aliquot of each cDNA sample $(1 \mu \mathrm{L})$ was amplified by $\mathrm{qPCR}$ in reaction mixtures containing primers (12 pmol each) and iQ SYBR Green Supermix (Bio-Rad). Sequences of the primers used in the qPCR reaction were as follows: human NOX4 forward: $5^{\prime}$ GTGGTGGTGCTATTCCTCAT-3', reverse: 5'-GCTGGTTCGGTTAAGACTGA-3'; human SOD-1 forward: $5^{\prime}$-GCGAGTTATGGCGACGAA-3', reverse: $5^{\prime}$-CAGTCAGTCCTTTAATGCTTCC-3 ${ }^{\prime}$; human VCAM-1 forward: $5^{\prime}$-ATGTAGTGTCATGGGCTGTG-3', reverse: $5^{\prime}$-GGAATGAGTAGAGCTCCACC-3'; human ICAM-1 forward: $5^{\prime}$-CCATCTACAGCTTTCCGGCGC-3', reverse: $5^{\prime}$-CTCTGGGGTGGCCTTCAGCA- $3^{\prime}$; human $\beta 2$-microglobulin $\left(\mathrm{B}_{2} \mathrm{M}\right)$ forward: $5^{\prime}$-CATCCAGCGTACTCCAAAGA, reverse: $5^{\prime}$ GACAAGTCTGAATGCTCCAC; and human GAPDH forward: $5^{\prime}$-CGATGCTGGCGCTGAGTACGT-3' , reverse: $5^{\prime}$ CCTGCAAATGAGCCCCAGCCTTC- $3^{\prime}$. Amplification was performed in a BioRad iQ5 thermocycler (Bio-Rad) using the following protocol: $95^{\circ} \mathrm{C}$ for $30 \mathrm{sec}$, Tm of specific primer sets for $30 \mathrm{sec}$, and $72^{\circ} \mathrm{C}$ for $30 \mathrm{sec}$. Relative changes in mRNA levels were determined by the $\Delta \Delta \mathrm{C}_{\mathrm{T}}$ method [10], using human $\mathrm{B}_{2} \mathrm{M}$ and GAPDH as the reference genes.
2.4. Monocyte Adhesion Assay. HCAECs were pretreated with HIPER $(25 \mu \mathrm{L} / \mathrm{mL})$ for $3 \mathrm{~h}$ before treated with TNF$\alpha(1 \mathrm{ng} / \mathrm{mL})$ for a further $3 \mathrm{~h}$. After treatment, monocyte to endothelial cell adhesion assays were performed as previously described [11].

2.5. Enzyme-Linked Immunosorbent Assay (ELISA). HCAECs were plated in 96-well plates and pretreated with HIPER $(25 \mu \mathrm{L} / \mathrm{mL})$ and for the MAP kinase experiments, either p38 MAP kinase inhibitor SB203580 (Calbiochem/ EMD Chemicals Inc., Gibbstown, NJ, USA) or MEK1/2 inhibitor UO126 (Calbiochem/EMD Chemicals Inc.) for $3 \mathrm{~h}$. All cells were then treated with TNF- $\alpha(1 \mathrm{ng} / \mathrm{mL})$ for a further $3 \mathrm{~h}$. After treatment, ELISA was performed as previously described for VCAM-1 and ICAM-1 [11]. I $\kappa \mathrm{B} \alpha$ levels were measured by FunctionELISA $\mathrm{I} \kappa \mathrm{B} \alpha$ (Active Motif, Carlsbad, CA, USA). p38 MAP kinase levels were measured by human/mouse phospho-p38 MAP kinase (T180/Y182) immunoassay (R\&D Systems Inc., Minneapolis, MN, USA). MEK1/2 levels were measured by the commercially available FACE MEK1/2 ELISA kit (Active Motif).

2.6. NF- $\kappa B$ Nuclear Translocation Assay. HCAECs were exposed to HIPER $(25 \mu \mathrm{L} / \mathrm{mL})$ for $3 \mathrm{~h}$ and then stimulated with TNF- $\alpha$ ( $1 \mathrm{ng} / \mathrm{mL})$ for $3 \mathrm{~h}$. After treatment, nuclear proteins were extracted using the NucBuster protein extraction kit (Merck Millipore) and nuclear NF- $\kappa \mathrm{B}$ levels were then determined as previously described [12].

2.7. Measurement of Intracellular Reactive Oxygen Species (ROS). Intracellular ROS levels were measured using the DCF assay (Thermo Fisher Scientific). HCAECs were pretreated with HIPER ( 25 or $50 \mu \mathrm{L} / \mathrm{mL}$ ) for $3 \mathrm{~h}$ before stimulation with TNF- $\alpha(5 \mathrm{ng} / \mathrm{mL})$ for a further $3 \mathrm{~h}$. After treatment, media were removed and cells washed with $1 \mathrm{x}$ PBS. $\mathrm{H}_{2}$ DCFDA stain (Thermo Fisher Scientific) was diluted in $1 \mathrm{x}$ PBS to a concentration of $10 \mu \mathrm{M}$ before treatment of cells. The cells were incubated at $37^{\circ} \mathrm{C}$ for $12 \mathrm{~min}$ before washing with $1 \mathrm{x}$ PBS and ROS level was determined by fluorescence measurement (485 nm/535 nm).

2.8. Statistical Analysis. All data are expressed as mean \pm SEM. Differences between conditions were determined by one-way ANOVA with Bonferroni's post hoc test analysis (GraphPad PRISM Software Version 4.03). Significance was set at $P<0.05$.

\section{Results}

3.1. HIPER Suppressed TNF- $\alpha$-Induced ROS Levels in HCAECs. TNF- $\alpha$ treatment of HCAECs increased ROS levels (Figure 1). Pretreatment with HIPER abrogated the TNF- $\alpha$ effect in a dose-dependent manner $(P<0.05)$.

3.2. HIPER Modulated the Expression of Enzymes Involved in the Oxidative Stress Response. TNF- $\alpha$ treatment increased NADPH oxidase 4 (NOX4) expression by $15 \%$, a result that was abrogated in HCAECs pretreated with 25 or $50 \mu \mathrm{L} / \mathrm{mL}$ 


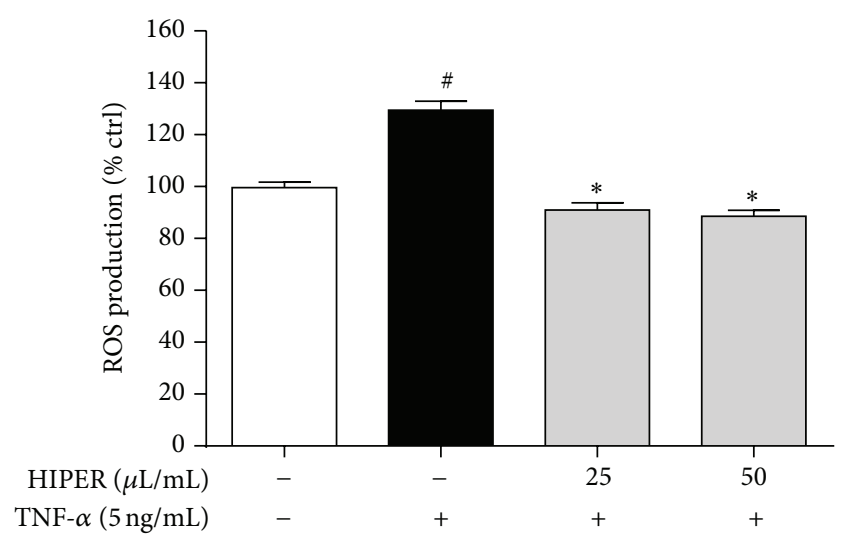

FIGURE 1: HIPER reduced ROS levels in TNF- $\alpha$-activated HCAECs. HCAECs were treated with HIPER at doses of 25 or $50 \mu \mathrm{L} / \mathrm{mL}$ for $3 \mathrm{~h}$ before activation with $5 \mathrm{ng} / \mathrm{mL}$ TNF- $\alpha$ for $3 \mathrm{~h}$. ROS levels were measured using the DCF assay. Data are shown as mean $\pm \operatorname{SEM}(n=$ 3). ${ }^{\#} P<0.05$ versus control, ${ }^{*} P<0.05$ versus TNF- $\alpha$.

HIPER for $3 \mathrm{~h}$ (Figure 2(a); $P<0.05$ ). In contrast, TNF$\alpha$ decreased superoxide dismutase-1 (SOD-1) expression by $24 \%$ (Figure 2(b); $P<0.05$ ), which was also abrogated by HIPER pretreatment at both the 25 and $50 \mu \mathrm{L} / \mathrm{mL}$ concentrations $(P<0.05)$.

3.3. HIPER Suppressed TNF- $\alpha$-Induced VCAM-1 and ICAM1 Expression and Monocyte Adhesion to HCAECs. HCAECs were pretreated with HIPER $(25 \mu \mathrm{L} / \mathrm{mL})$ and then stimulated with TNF- $\alpha$. Figures 3(a) and 3(b) show that there was a dosedependent decrease in ICAM-1 (a) and VCAM-1 (b) mRNA levels in response to HIPER. The decrease in mRNA levels correlated with a decrease in protein as measured by ELISA where HIPER $(25 \mu \mathrm{L} / \mathrm{mL})$ reduced ICAM-1 protein levels by 25\% (Figure 3(c); $P<0.05$ ) and VCAM-1 protein levels by $18 \%$ (Figure 3(d); $P<0.5$ ).

Figure 4 shows that TNF- $\alpha$ stimulated monocyte adhesion to HCAECs by 8.5 -fold $(P<0.05)$. Pretreatment of HCAECs with HIPER $(25 \mu \mathrm{L} / \mathrm{mL})$ suppressed TNF- $\alpha$ stimulated monocyte adhesion by 2 -fold $(P<0.05)$.

3.4. HIPER Suppressed TNF- $\alpha$-Stimulated NF- $\kappa B$ Activation. Given that HIPER suppressed TNF- $\alpha$-induced ROS levels and VCAM-1 and ICAM-1 expression, it was next explored whether HIPER suppressed TNF- $\alpha$-induced NF$\kappa \mathrm{B}$ activation. In its inactivated state, $\mathrm{NF}-\kappa \mathrm{B}$ is bound by an inhibitor protein, $\mathrm{I} \kappa \mathrm{B} \alpha$. In inflammatory conditions, cell signalling cascades that involve MAP kinases lead to the phosphorylation of $\mathrm{I} \kappa \mathrm{B} \alpha$ [13]. Phosphorylated $\mathrm{I} \kappa \mathrm{B} \alpha$ is targeted for degradation freeing NF- $\kappa \mathrm{B}$ to translocate to the nucleus to active target gene expression that includes VCAM1 and ICAM-1. Figure 5(a) shows that TNF- $\alpha$ significantly increased NF- $\kappa \mathrm{B}$ nuclear activation by $70 \%(P<0.05)$ and that pretreatment of HCAECs with HIPER $(25 \mu \mathrm{L} / \mathrm{mL})$ decreased this effect by $43 \%(P<0.05)$. Figure $5(\mathrm{~b})$ shows that the effect of HIPER on suppressing NF- $\kappa$ B activation was associated with a decrease in phosphorylated $\mathrm{I} \kappa \mathrm{B} \alpha$, the inhibitor protein of NF- $\kappa$ B. Phosphorylation of $\mathrm{I} \kappa \mathrm{B} \alpha$ is driven by MAP kinase activation. Figures 5(c) and 5(d) show that HIPER suppressed p38 and MEK1/2 MAP kinases activation almost to the same basal level as the p38 inhibitor SB203580 or the MEK1/2 inhibitor, UO126. Together, this data suggests that HIPER suppresses the HCAECs inflammatory response, at least in part, via suppression of MAP kinase and NF- $\kappa \mathrm{B}$ activation.

3.5. PBE Is Central to the Anti-Inflammatory Effect of HIPER. To test each HIPER ingredient for an individual antiinflammatory effect, HCAECs were exposed to either PBE $(130 \mu \mathrm{g} / \mathrm{mL}$ or $260 \mu \mathrm{g} / \mathrm{mL})$, aloe vera $(1.75 \mathrm{mg} / \mathrm{mL})$, honey $(0.1 \%)$, or papain $(2.4 \mathrm{mg} / \mathrm{mL})$ for $3 \mathrm{~h}$ before being activated with TNF- $\alpha(1 \mathrm{ng} / \mathrm{mL})$ for a further $3 \mathrm{~h}$. The antiinflammatory effect of each individual component was compared to each other and to the parent compound, HIPER $(25 \mu \mathrm{L} / \mathrm{mL})$. Figure 6 shows that HIPER $(25 \mu \mathrm{L} / \mathrm{mL})$ and PBE (at both concentrations) decreased TNF- $\alpha$-induced VCAM1 mRNA levels. PBE was twice as effective as HIPER in decreasing TNF- $\alpha$-induced VCAM-1 expression (1.5-fold versus 3 -fold, resp., $P<0.05)$. Honey and aloe vera showed a nonsignificant trend towards decreased VCAM-1 mRNA levels. By contrast, papain increased VCAM-1 mRNA levels (1.5-fold, $P<0.05)$ over and above expression levels induced by $\mathrm{TNF}-\alpha$.

\section{Discussion}

Extracts from natural substances may have the potential to complement mainstream medicine. In the present study, it was shown that HIPER Health Supplement, comprised of PBE, honey, aloe vera, and papain, decreased TNF$\alpha$-induced ROS levels that was associated with decreased ICAM-1 and VCAM-1 expression as well as decreased MAP kinase and NF- $\kappa$ B activation. The physiologic consequence of the HIPER-mediated suppressed inflammatory response was decreased monocyte adhesion to HCAECs, which suggests improved endothelial cell function. Although this project was solely conducted with an in vitro model of cultured HCAECs, the findings suggest that HIPER may have potential to decrease key early steps in the pathogenesis of atherosclerosis, specifically the binding of monocytes to coronary artery endothelial cells.

In this study, we have shown that HIPER, a mixture of PBE, honey, aloe vera, and papain, has significant anti-inflammatory and antioxidant effects. Pretreatment of HCAECs to HIPER, at doses in keeping with the recommended daily dosage for human consumption, suppressed TNF- $\alpha$-induced MAP kinase and NF- $\kappa$ B activation that, in turn, decreased ICAM-1 and VCAM-1 expression, thereby decreasing monocyte adhesion. We further showed that HIPER suppressed ROS levels in TNF- $\alpha$-activated HCAECs, possibly via modulation of key enzymes involved in superoxide generation and degradation. Potentially, this antioxidant property of HIPER may underlie the anti-inflammatory effects.

Investigation of the individual components showed that while PBE, honey, and aloe vera were anti-inflammatory, 


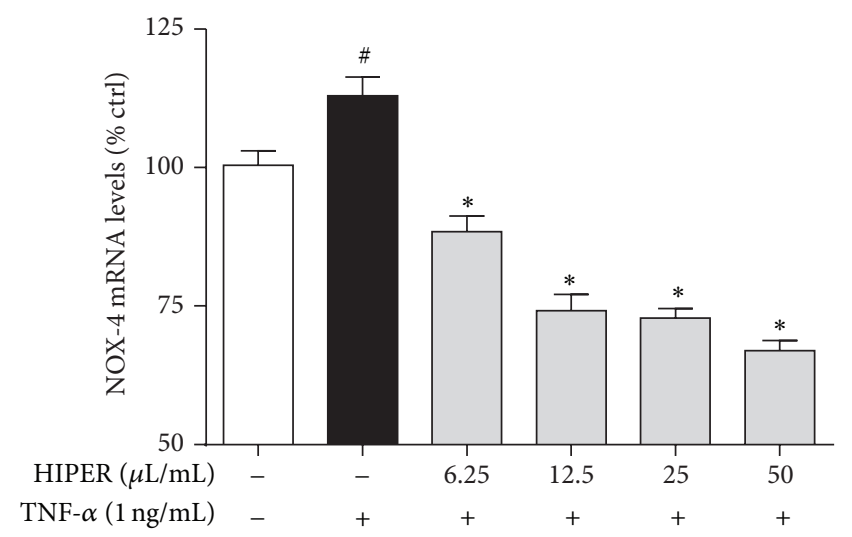

(a)

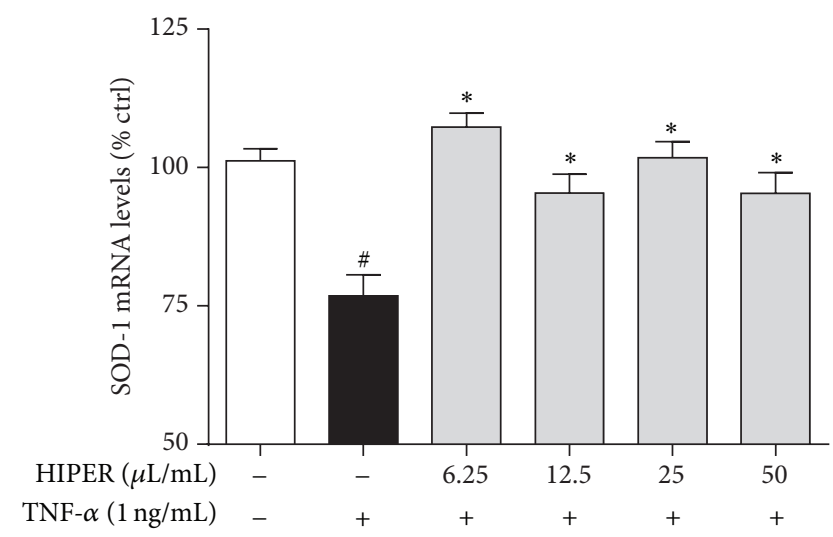

(b)

FIgURE 2: HIPER modulated NOX4 and SOD1 mRNA levels in TNF- $\alpha$-activated HCAECs. HCAECs were treated with HIPER at concentrations of $6.25,12.5,25$, and $50 \mu \mathrm{L} / \mathrm{mL}$ for $3 \mathrm{~h}$, before activation with $1 \mathrm{ng} / \mathrm{mL}$ TNF- $\alpha$ for $1 \mathrm{~h}$. Total RNA was extracted and NOX4 (a) and SOD-1 (b) mRNA levels were measured by RT-qPCR. Data are shown as mean \pm SEM $(n=3)$. ${ }^{\#} P<0.05$ versus control, ${ }^{*} P<0.05$ versus TNF- $\alpha$.

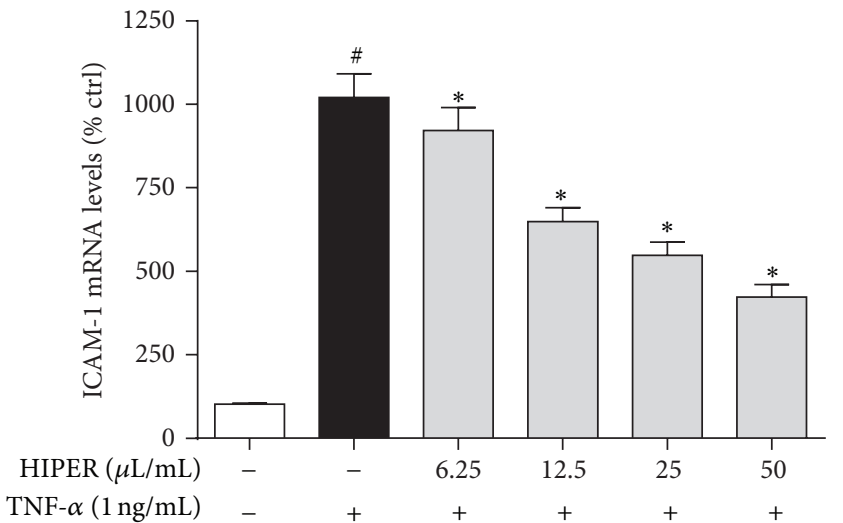

(a)

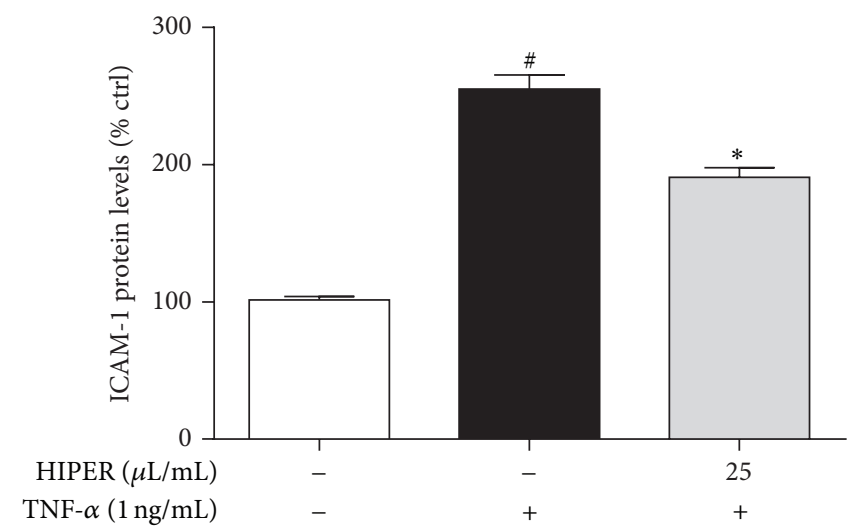

(c)

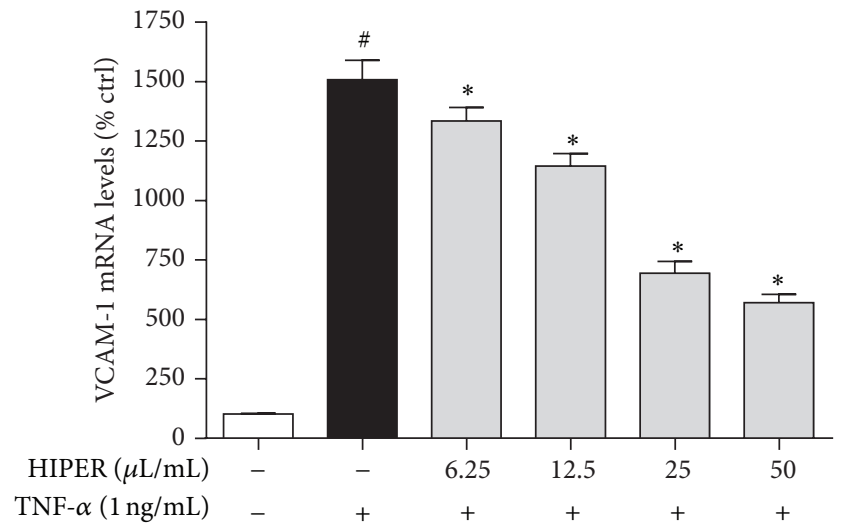

(b)

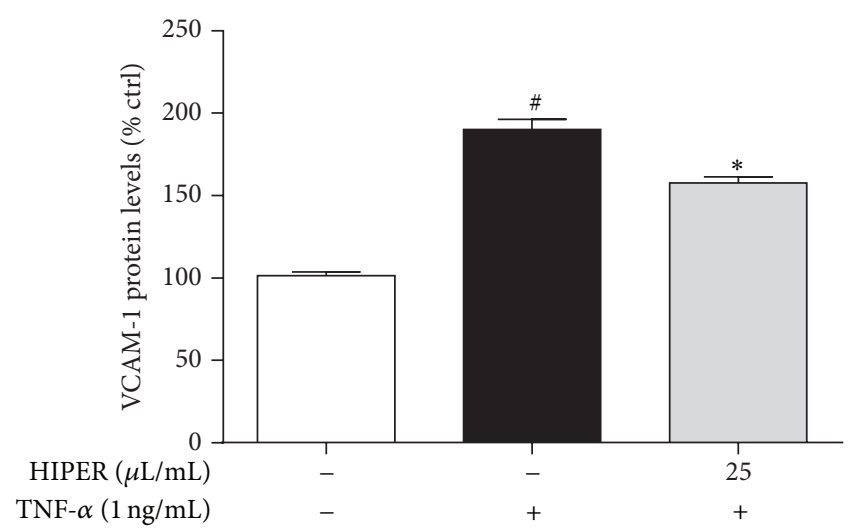

(d)

FIGURE 3: HIPER reduced ICAM-1 and VCAM-1 mRNA and protein levels in TNF- $\alpha$-activated HCAECs. HCAECs were treated with HIPER at doses of $6.25,12.5,25$, and $50 \mu \mathrm{L} / \mathrm{mL}$ for $3 \mathrm{~h}$, before activation with TNF- $\alpha(1 \mathrm{ng} / \mathrm{mL})$ for 1 or $3 \mathrm{~h}$ for mRNA or protein levels, respectively. Total RNA was extracted and ICAM-1 (a) or VCAM-1 (b) mRNA levels were measured by RT-qPCR. Cell-based ELISA was used to measure ICAM-1 (c) and VCAM-1 (d) protein levels. Data are shown as mean \pm SEM $(n=3) .{ }^{*} P<0.05$ versus control, ${ }^{*} P<0.05$ versus TNF- $\alpha$. 


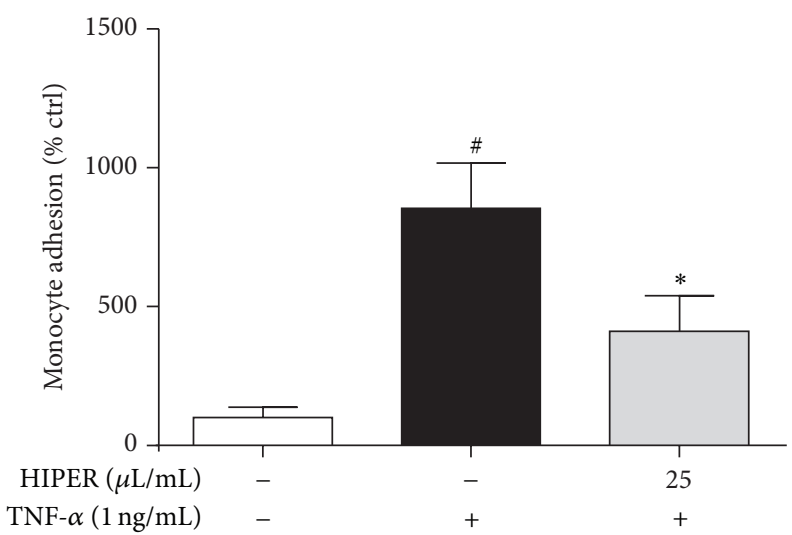

FIGURE 4: HIPER reduced monocyte adhesion to TNF- $\alpha$-activated HCAECs. HCAECs were treated with HIPER at a dose of $25 \mu \mathrm{L} / \mathrm{mL}$ for $3 \mathrm{~h}$, before activation with TNF- $\alpha(1 \mathrm{ng} / \mathrm{mL})$ for $3 \mathrm{~h}$. HCAECs were then exposed to monocytes $\left(1 \times 10^{6} \mathrm{cells} / \mathrm{mL}\right)$ for $1 \mathrm{~h}$ after which nonadhered monocytes were removed and the percentage of adherent monocytes calculated. Data are shown as mean \pm SEM $(n=3)$. ${ }^{\#} P<0.005$ versus control, ${ }^{*} P<0.05$ versus TNF- $\alpha$.

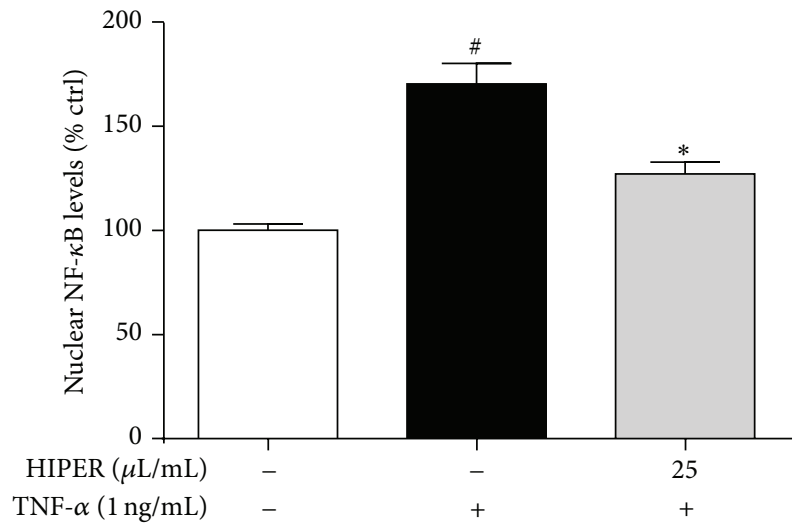

(a)

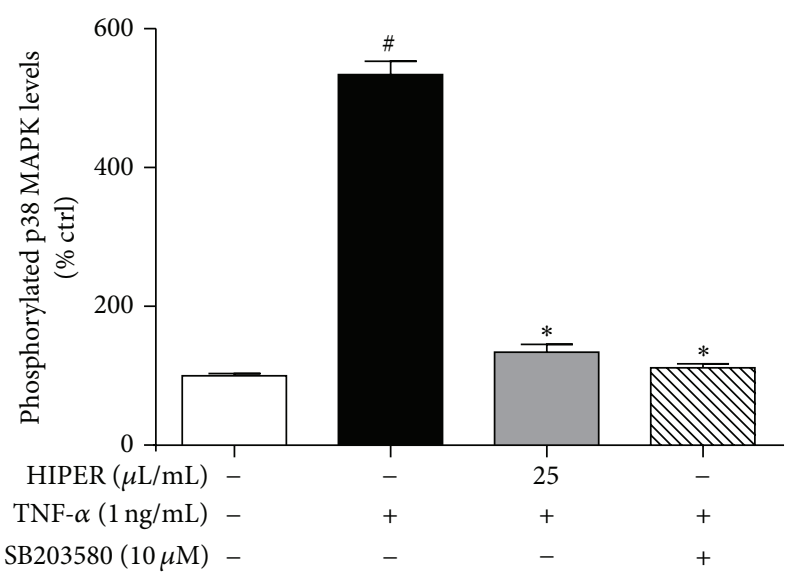

(c)

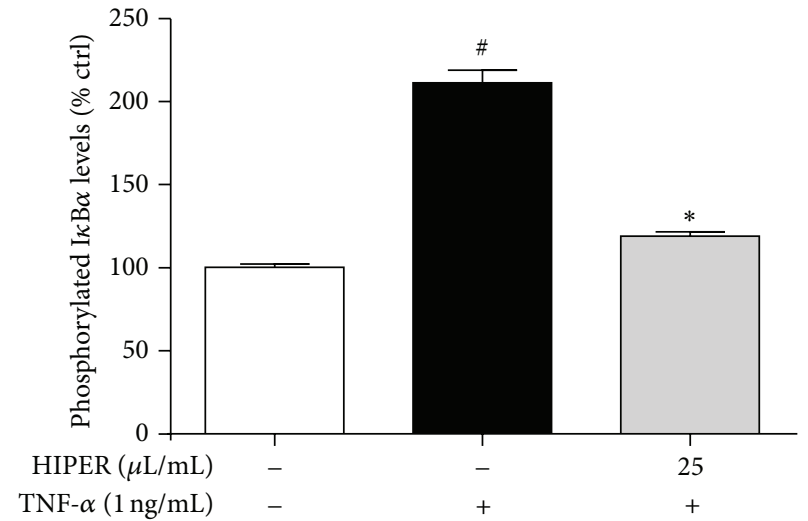

(b)

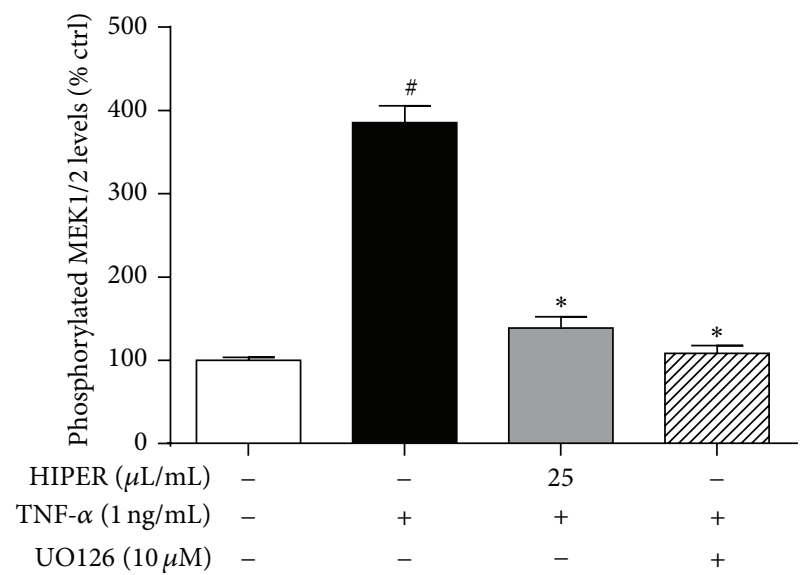

(d)

FIGURE 5: HIPER reduced NF- $\kappa$ B activation in TNF- $\alpha$-activated HCAECs. HCAECs were treated with HIPER at a dose of $25 \mu \mathrm{L} / \mathrm{mL}$ for $3 \mathrm{~h}$, before activation with $1 \mathrm{ng} / \mathrm{mL}$ TNF- $\alpha$ for $3 \mathrm{~h}$. For (c) additional cells were treated with SB203580 (10 $\mu \mathrm{M})$ and (d) UO126 (10 $\mu \mathrm{M})$. For (a) nuclear extract was obtained and NF- $\kappa$ B levels were measured using commercially available NoShift assay. For (b)-(d), cultured cells were used directly in commercially available ELISA kits. Data are shown as mean \pm SEM $(n=3)^{*} P<0.05$ versus control, ${ }^{\#} P<0.05$ versus TNF- $\alpha$. 


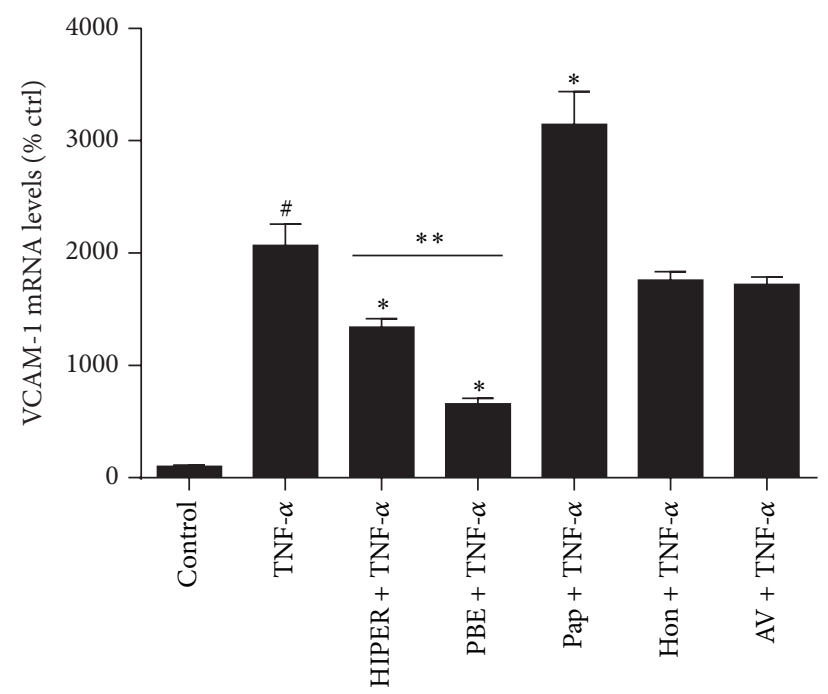

FIGURE 6: Anti-inflammatory effects of individual HIPER components. HCAECs were treated with HIPER or pine bark extract (PBE), papain (Pap), honey (Hon), or aloe vera (AV) for $3 \mathrm{~h}$ and then activated with $1 \mathrm{ng} / \mathrm{mL}$ TNF- $\alpha$ for $1 \mathrm{~h}$. Total RNA was extracted and VCAM-1 mRNA levels were measured by RT-qPCR. Data are shown as mean $\pm \operatorname{SEM}(n=3)$. ${ }^{\#} P<0.05$ versus control, ${ }^{*} P<0.05$ versus TNF- $\alpha$, and ${ }^{* *} P<0.05$ HIPER versus PBE.

albeit to different extents, papain was proinflammatory. This is in keeping with its enzymatic role as a peptidase [14]. The use of papain in HIPER, therefore, requires further investigation as our findings suggest adverse effects that are potentially decreasing the efficacy of complete HIPER. On the other hand, PBE was shown to be very effective at attenuating VCAM-1 mRNA levels. PBE is extracted from the bark of the French maritime pine tree, Pinus pinaster, and is commercially available as a herbal dietary supplement (registered trade name: Pycnogenol). It is already in use for the treatment of many inflammatory, autoimmune, and cardiovascular disorders $[8,9,15-17]$ and very recently it was shown to reduce atherosclerotic lesion burden in a small clinical study [18]. PBE is increasingly recognised for its antiinflammatory and antioxidant effects in vitro and in vivo (reviewed in [9]). For example, in vitro studies have shown that $\mathrm{PBE}$ reduces cell adhesion molecule expression in human umbilical vein endothelial cells through suppression of NF$\kappa \mathrm{B}$ [19], which is in keeping with our current findings for HIPER that show decreased NF- $\kappa$ B activation and decreased CAM expression in HCAECs. Similarly, in vitro studies have demonstrated that PBE reduces ROS levels in renal tubular cells in association with decreased lipid peroxidation [20], again in accordance with our data for HIPER showing decreased ROS levels in HCAECs. In vivo, a recent randomized, double-blind, placebo-controlled crossover showed that 8 weeks of Pycnogenol treatment $(200 \mathrm{mg} /$ day) improves endothelial function in patients with coronary artery disease by reducing oxidative stress [21]. Therefore, it would now be prudent not only to test whether HIPER is able to recapitulate its in vitro effects when administered in vivo but also to test whether synergistic actions between PBE, honey, and aloe vera occur in vivo.

Limitations of our study include the facts that that it is an in vitro investigation and the bioavailability and/or bioactivation of HIPER and its components were not investigated. In this study HCAECs were directly treated with the HIPER to investigate the effects. However, in vivo, HIPER would be digested and metabolized by the liver that may generate metabolites that provide further or no benefit. Therefore, effects of direct HIPER exposure on HCAECs may differ from the effects when HCAECs are exposed to the metabolites of HIPER.

In conclusion, our results demonstrate the antiinflammatory and antioxidant potential of HIPER containing the natural products, $\mathrm{PBE}$, honey, aloe vera, and papain. Our finding that HIPER has a potent ability to decrease NF- $\kappa$ B and MAP kinase activation, and therefore inflammatory gene expression, suggests that HIPER could be beneficial against a number of inflammatory conditions where cell adhesion molecules and monocyte adhesion are an underlying pathogenic mechanism that includes atherosclerosis. Endothelial cell dysfunction resulting in the local recruitment of leukocytes to sites of inflammatory challenge is a crucial step in the initiation of the atherosclerotic process, as well as the development of advanced atherosclerosis [22]. Therefore, it would be worth investigating further the effects of HIPER on suppressing early atherosclerotic lesion formation in an in vivo model.

\section{Conflict of Interests}

The authors certify that they do not have a direct financial relationship with Plasmaide Pty Ltd. and have no other conflict of interests in connection with the submitted paper.

\section{Acknowledgment}

The authors would like to thank Plasmaide Pty Ltd. for the donation of HIPER and the individual components contained within HIPER.

\section{References}

[1] R. Rezzani, F. Bonomini, S. Tengattini, A. Fabiano, and R. Bianchi, "Atherosclerosis and oxidative stress," Histology and Histopathology, vol. 23, no. 3, pp. 381-390, 2008.

[2] R. Paoletti, A. M. Gotto Jr., and D. P. Hajjar, "Inflammation in atherosclerosis and implications for therapy," Circulation, vol. 109, no. 23, supplement 1, pp. III20-III26, 2004.

[3] P. Libby, "Inflammation and cardiovascular disease mechanisms," The American Journal of Clinical Nutrition, vol. 83, no. 2, pp. 456S-460S, 2006.

[4] H. M. Dansky, C. B. Barlow, C. Lominska et al., "Adhesion of monocytes to arterial endothelium and initiation of atherosclerosis are critically dependent on vascular cell adhesion molecule-1 gene dosage," Arteriosclerosis, Thrombosis, and Vascular Biology, vol. 21, no. 10, pp. 1662-1667, 2001.

[5] R. Prabjone, D. Thong-Ngam, N. Wisedopas, T. Chatsuwan, and S. Patumraj, "Anti-inflammatory effects of Aloe vera on 
leukocyte-endothelium interaction in the gastric microcirculation of Helicobacter pylori-infected rats," Clinical Hemorheology and Microcirculation, vol. 35, no. 3, pp. 359-366, 2006.

[6] B. V. Owoyele, O. T. Adenekan, and A. O. Soladoye, "Effects of honey on inflammation and nitric oxide production in Wistar rats," Zhong Xi Yi Jie He Xue Bao, vol. 9, no. 4, pp. 447-452, 2011.

[7] M. I. Khalil, S. A. Sulaiman, and L. Boukraa, "Antioxidant properties of honey and its role in preventing health disorder," The Open Nutraceuticals Journal, vol. 3, no. 1, pp. 6-16, 2010.

[8] I. Ince, O. Yesil-Celiktas, N. U. Karabay-Yavasoglu, and G. Elgin, "Effects of Pinus brutia bark extract and Pycnogenol in a rat model of carrageenan induced inflammation," Phytomedicine, vol. 16, no. 12, pp. 1101-1104, 2009.

[9] A. Maimoona, I. Naeem, Z. Saddiqe, and K. Jameel, "A review on biological, nutraceutical and clinical aspects of French maritime pine bark extract," Journal of Ethnopharmacology, vol. 133, no. 2, pp. 261-277, 2011.

[10] S. A. Bustin, "Absolute quantification of mRNA using real-time reverse transcription polymerase chain reaction assays," Journal of Molecular Endocrinology, vol. 25, no. 2, pp. 169-193, 2000.

[11] A. K. Death, K. C. Y. McGrath, M. A. Sader et al., "Dihydrotestosterone promotes vascular cell adhesion molecule-1 expression in male human endothelial cells via a nuclear factorkappaB-dependent pathway," Endocrinology, vol. 145, no. 4, pp. 1889-1897, 2004.

[12] K. C. McGrath, X. H. Li, P. T. Whitworth et al., "High density lipoproteins improve insulin sensitivity in high-fat diet-fed mice by suppressing hepatic inflammation," Journal of Lipid Research, vol. 55, no. 3, pp. 421-430, 2014.

[13] I. Stancovski and D. Baltimore, "NF- $\kappa$ B activation: the I $\kappa$ B kinase revealed?” Cell, vol. 91, no. 3, pp. 299-302, 1997.

[14] O. P. Gupta, N. Sharma, and D. Chand, "A sensitive and relevant model for evaluating anti-inflammatory activity-papaya latexinduced rat paw inflammation," Journal of Pharmacological and Toxicological Methods, vol. 28, no. 1, pp. 15-19, 1992.

[15] Y. H. Choi and G. H. Yan, "Pycnogenol inhibits immunoglobulin E-mediated allergic response in mast cells," Phytotherapy Research, vol. 23, no. 12, pp. 1691-1695, 2009.

[16] A. Schoonees, J. Visser, A. Musekiwa, and J. Volmink, "Pycnogenol (extract of French maritime pine bark) for the treatment of chronic disorders for the treatment of chronic disorders," Cochrane Database of Systematic Reviews, vol. 4, Article ID CD008294, 2012.

[17] G. D’Andrea, "Pycnogenol: a blend of procyanidins with multifaceted therapeutic applications?" Fitoterapia, vol. 81, no. 7, pp. 724-736, 2010.

[18] G. Belcaro, M. Dugall, M. Hosoi et al., "Pycnogenol and Centella Asiatica for asymptomatic atherosclerosis progression," International Angiology, vol. 33, no. 1, pp. 20-26, 2014.

[19] Q. Peng, Z. Wei, and B. H. S. Lau, "Pycnogenol inhibits tumor necrosis factor-alpha-induced nuclear factor kappa B activation and adhesion molecule expression in human vascular endothelial cells," Cellular and Molecular Life Sciences, vol. 57, no. 5, pp. 834-841, 2000.

[20] Y. J. Kim, Y. A. Kim, and T. Yokozawa, "Pycnogenol modulates apoptosis by suppressing oxidative stress and inflammation in high glucose-treated renal tubular cells," Food and Chemical Toxicology, vol. 49, no. 9, pp. 2196-2201, 2011.

[21] F. Enseleit, I. Sudano, D. Périat et al., "Effects of Pycnogenol on endothelial function in patients with stable coronary artery disease: a double-blind, randomized, placebo-controlled, crossover study," European Heart Journal, vol. 33, no. 13, pp. 15891597, 2012.

[22] R. Ross, "Atherosclerosis-an inflammatory disease," The New England Journal of Medicine, vol. 340, no. 2, pp. 115-126, 1999. 


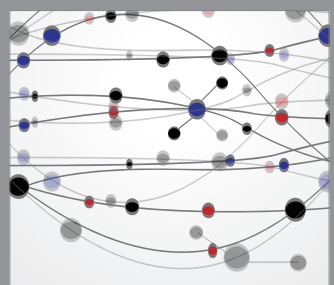

The Scientific World Journal
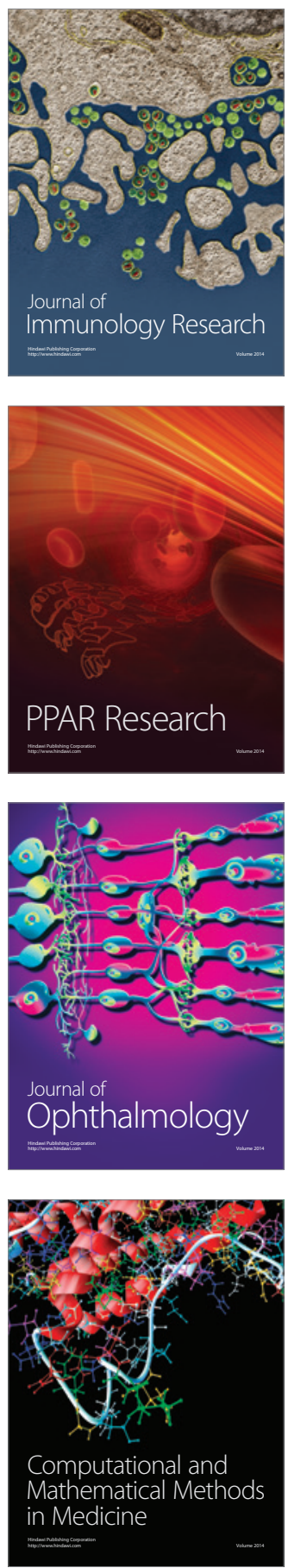

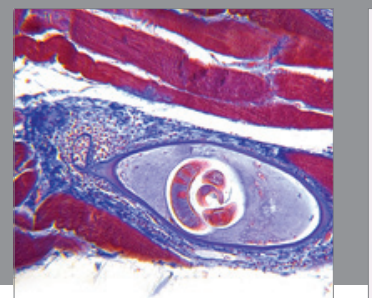

Gastroenterology

Research and Practice
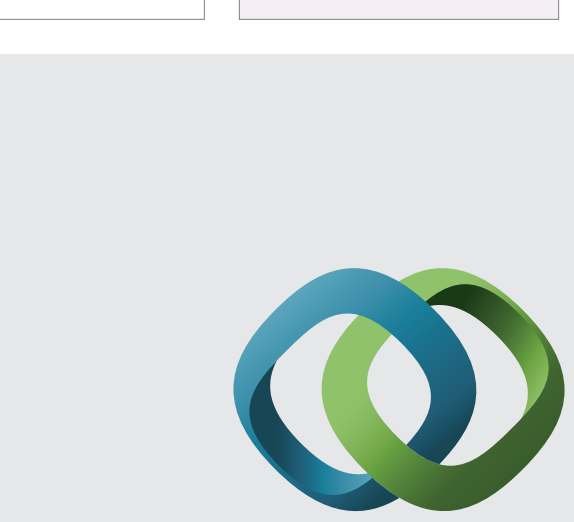

\section{Hindawi}

Submit your manuscripts at

http://www.hindawi.com
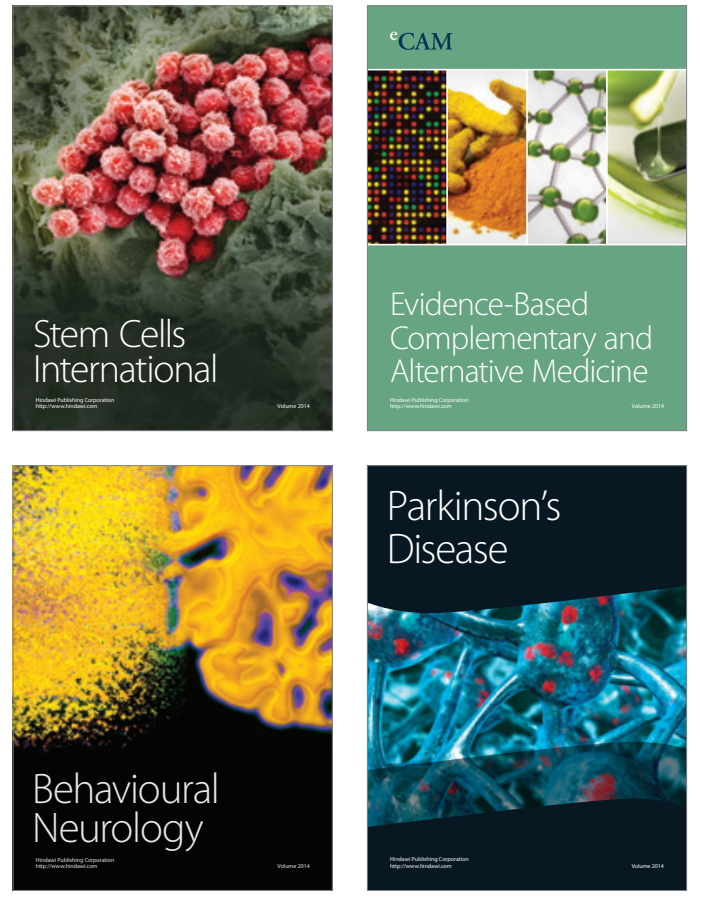
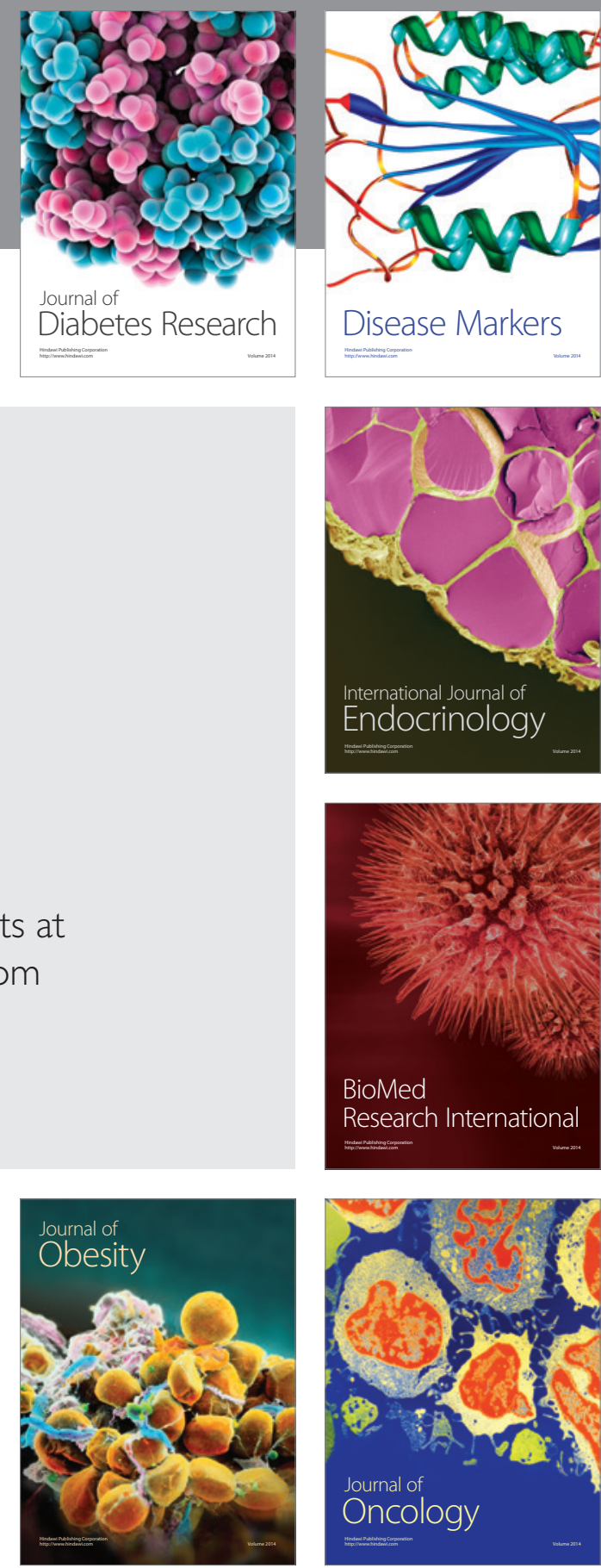

Disease Markers
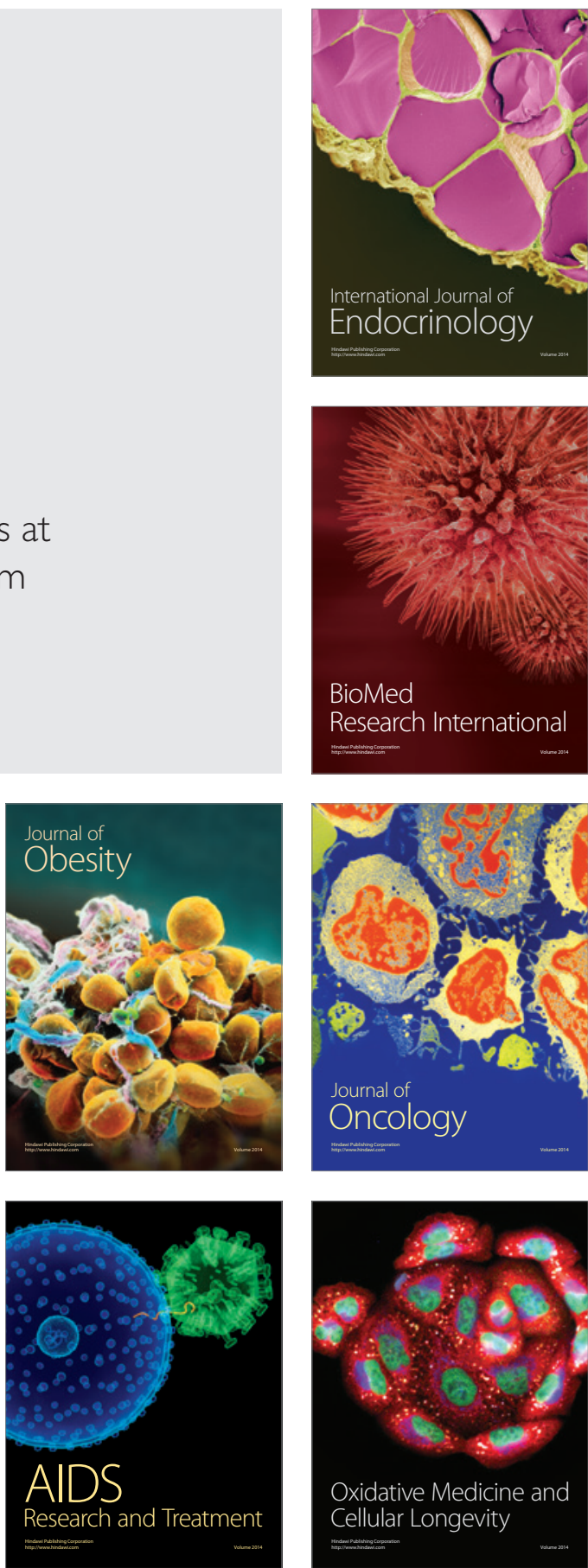